\title{
Integration of a Mindfulness Meditation Lab for University Students
}

\author{
Duke D. Biber, PhD \\ Sport Management, Wellness, and Physical Education \\ College of Education \\ University of West Georgia
}

\begin{abstract}
Background: Mindfulness meditation can effectively enhance every dimension of holistic wellness and learning, including cognition, attention, self-regulatory resources, and first-year academic success.

Aim: This paper discusses the potential impact of a mindfulness meditation room on student wellness, education, experiential learning, and development.

Methods: The program curriculum and the structure of the Wolf Wellness Lab at the University of West Georgia emphasizes a holistic approach to higher education curriculum development and student wellness and is based on the National Wellness Institute's six dimensions of wellness. The newly developed mindfulness meditation room is discussed in regard to recent research and valid, practical application as a way to improve student learning and overall wellness.

Conclusions: The mindfulness meditation room provides experiential learning and high-impact practices associated with the University of West Georgia educational curriculum. The mindfulness meditation room could promote student learning and overall well-being via personal practice and opportunities to guide other students and faculty through meditation practice.
\end{abstract}

Submitted 15 May 2020: accepted 28 June 2020

Keywords: mindfulness, wellness, experiential learning, college

Effective university curriculum typically offers broad exposure to a variety of disciplines that promote learning, practical and real-world application, and civic engagement (AACU, 2015). Incorporating high-impact practices into education can improve student learning and mental health (Finley \& McNair, 2013; Stebleton, Soria, \& Huesman, 2014). Furthermore, education that emphasizes holistic wellness has been found to positively impact college student mental health, sense of belonging, confidence, and civic engagement (Fink, 2014).

The National Wellness Institute (NWI) emphasizes a holistic approach to higher education curriculum development and student wellness, which incorporates personal learning and growth across a variety of areas (Biber et al., 2018; Goss, Cuddihy, \& Michaud-Tomson, 2010; NWI, 2018). The NWI's holistic approach to wellness is consistent with research indicating the importance of applied wellness education on student outcomes (Hager, George, LeCheminant, Bailey, \& Vincent, 2012). The NWI emphasizes emotional, occupational, spiritual, intellectual, social, and physical health promotion (Strout \& Howard, 2012). Teaching NWI's holistic wellness framework helps students become aware of each separate component of wellness as well as the interconnectedness of wellness. Previous research indicates the importance of health education on motivation to stay in college and retention (Porter 
\& Swing, 2006). The Wolf Wellness Lab (WWL) at the University of West Georgia emphasizes a holistic approach to student learning and is based on the NWI's six dimensions of wellness (Biber et al., 2018).

Through education and the WWL, students have had the opportunity to participate in a variety of high-impact practices, including the provision of health services, wellness education, engaging in student leadership, and advocacy of community wellness, each of which promotes holistic health and learning. Such high-impact practices benefit academic and social-emotional learning when incorporated in university settings (Conley, Durlak, \& Dickson, 2013). While high-impact practices can promote learning and well-being, research has found that social and emotional health declines throughout college and additional resources need to be made available to students to promote flourishing (Conley, Kirsch, Dickson, \& Bryant, 2014; Durlak, Weissberg, Dymnicki, Taylor, \& Schellinger, 2011; Zins, Weissberg, Wang, \& Wahlberg, 2004). One resource that has recently been added to the WWL that will contribute to education, practice, and well-being of students is a mindfulness meditation room. Mindfulness meditation can effectively enhance every dimension of holistic wellness and learning, including cognition, attention, self-regulatory resources, and first-year academic success, which is why funding was approved to integrate such a room into the WWL (Rosenstreich \& Magalit, 2015).

\section{WHAT IS MINDFULNESS?}

Mindfulness is the process of "paying attention in a particular way: on purpose, in the present moment, and nonjudgmentally" (Kabat-Zinn, 1994, p. 4). Mindfulness involves three components: intention, attention, and attitude (Shapiro, Soria, \& Huesman, 2006). Intention is comprised of commitment and dedication to mindful meditation practice. Attention involves observing the contents of one's current experience. Attitude is related to how a person pays attention to their current experience (i.e. non-judgmentally). While much of the mindfulness research is based in Buddhism, it is necessary to understand that mindfulness can be regarded from any spiritual discipline or practice (Grossman \& Van Dam, 2011; Kang \& Whittingham, 2010).

\section{BENEFITS OF MINDFULNESS}

Mindfulness has many proven benefits, including stress management, anxiety reduction, and learning in college (Bamber \& Schneider, 2016; Dvořáková et al., 2017; Lynch, Gander, Kohls, Kudeilka, \& Walach, 2011; Regehr, Glancy, \& Pitts, 2013; Rosenstreich \& Margalit, 2015). Mindfulness has also been found to improve self-confidence, optimism, happiness, self-esteem, on-task behavior and attention, and relationships with others (Fisher, 2006; Schonert-Reichl \& Lawlor, 2010). Much of this research has been conducted in primary, secondary, and higher education, with mindfulness having a positive impact on cognitive functioning, academic performance, stress reduction and regulation, and the development of the individual from a holistic perspective (Shapiro, Brown, \& Astin, 2011). Mindfulness has the potential to improve stress resiliency in university students, helping them overcome barriers to success and the transition from high school to independent life. Based on the three components of mindfulness, such training will help university students become more accepting of their thoughts, feelings, and behaviors associated with such a transition (Grossman \& Van Dam, 2011). Overall, mindfulness practice can promote personal responsibility and lifelong learning during the first two years of college (i.e. general education curriculum), potentially increasing retention and graduation (Whitehall, Hill, Yost, \& Kidwell, 2018). 


\section{INTENDED USE OF THE MINDFULNESS MEDITATION ROOM}

The mindfulness meditation room in the WWL will be free to use for university students during the operating hours of the lab (Monday-Friday; 9:00a.m. - 5:00p.m.). The open-access and foundation of unconditional positive regard, acceptance, and introspection of this resource will help to engage students of all grade levels, races, religions, and sexual orientations (Quaye \& Harper, 2014). Students will have the opportunity to reserve the mindfulness meditation room in 20-minute increments, with a maximum capacity of three students per reservation. Students will have access to mindfulness podcasts, self-compassion podcasts, headphones and a speaker to play guided meditations or relaxing music, a comfortable setting and a relaxing aroma, and a compilation of mindfulness exercises ranging from 5 minutes to 20 minutes in duration. Students will not be allowed to use the room for homework, studying, talking with other students, nor will they be able to use their phones to text or make calls while using the room. The mindfulness meditation room is intended for the increase in intention, attention, and attitude towards mindfulness training. Students will be welcome to sit in silent meditation or use any and all of the aforementioned resources. If any student wants assistance in learning about mindfulness, they will be allowed to schedule time with faculty trained in mindfulness and self-compassion. Such assistance can establish faculty-student engagement, high-impact learning, and promote social support and connectivity between students (Tinto, 1997). Overall, this meditation room will provide students an opportunity to remove distractions, sit in reflective meditation, and begin to pay attention with intention and an unconditional attitude (Shapiro et al., 2006).

\section{STUDENT OUTCOMES}

Through the implementation of a mindfulness meditation room, students will have the opportunity to engage in valid and reliable, research-based programs and interventions to improve mindfulness, stress management, social connectivity, and academic success, among other benefits. The programs and interventions will be chosen by the WWL's research and teaching faculty who have extensive training and expertise in mindfulness, meditation, and selfcompassion. Mindfulness programs will only be implemented if proven to have a valid and reliable impact based on scholarly, peer-reviewed research. The fidelity and effectiveness of the mindfulness training will be evaluated through the Institutional Review Board and the co-research directors of the lab. Overall, the mindfulness meditation room will foster every component of the NWI's definition of wellness (Table 1). Students will have the ability to practice self-regulation of health behaviors, mindfulness of thoughts, feelings, and behaviors to engage in high-impact practices throughout their education (Finley \& McNair, 2013). The initial goal of the space is to help students engage in mindfulness training in an unconditional, positive regard, with openness, honesty, and curiosity, which can positively impact attitude, attention, and intention towards learning (Eisenberg, Golberstein, \& Hunt 2009). 
Table 1

Impact of Mindfulness Meditation Room

\begin{tabular}{|l|l|}
\hline National Wellness Institute Dimension & Description \\
\hline Emotional Wellness & $\begin{array}{l}\text { Reduce anxiety, depression, stress, and improve } \\
\text { empathy and self-regulation of emotions }\end{array}$ \\
\hline Social Wellness & $\begin{array}{l}\text { Improve behavioral regulation, physical activity } \\
\text { behavior, sleep behavior, nutritional choices, and } \\
\text { physiological health }\end{array}$ \\
\hline Intellectual Wellness & $\begin{array}{l}\text { Promote self-awareness, socially competent } \\
\text { behaviors, self-confidence, and social relatedness }\end{array}$ \\
\hline Spiritual Wellness & $\begin{array}{l}\text { Improve cognitive performance, on-task behavior, } \\
\text { reduce academic stress, academic performance, and } \\
\text { sustained focused attention }\end{array}$ \\
\hline Occupational Wellness & $\begin{array}{l}\text { Improve optimism, happiness, gratitude, empathy, } \\
\text { connectedness with a higher power, and spiritual } \\
\text { reflection. }\end{array}$ \\
\hline
\end{tabular}

\section{COMMUNITY IMPACT}

The mindfulness meditation room will provide a multitude of opportunities for high-impact, experiential learning, which is an important component of successful college education (Hart Research Associates, 2009). Students majoring in Health and Community Wellness will have the opportunity to work as paid employees of the WWL and mindfulness meditation room. Student employees will be in charge of helping other undergraduates reserve the mindfulness meditation room, promoting the room and the benefits of use across campus. Furthermore, students will have the opportunity to become certified and master trainers in a variety of mindfulness-based programs that will also be offered to the community at low-cost. Such certifications and service-learning opportunities are a crucial component of student learning, real-world application, and education (Bush, 2011; Whitehall et al., 2018). Students will gain experience training community members in mindfulness, which will further their personal mindfulness practice and holistic health. As with the other services of the Wolf Wellness Lab, it is necessary for community members to receive informational and behavioral interventions to promote holistic health (Biber et al., 2018). This lab extension will offer such techniques at an affordable, easy-to-access manner.

\section{CONCLUSIONS AND FUTURE RESEARCH}

The goal of this paper was to describe the integration of a mindfulness meditation room as part of a university-based, holistic wellness lab that can complement and enhance higher education curriculum, experiential-learning, and wellbeing. The mindfulness meditation room is run by students, for students, to promote holistic wellness as outlined by the NWI. Integration of such a resource will promote mindfulness, high-impact learning, and incorporation of 
mindfulness into the education development (Broderick \& Metz, 2009). Future research will be conducted using the RE-AIM (reach, efficacy, adoption, implementation, and maintenance) framework to determine usage rate and impact of the mindfulness meditation room in a university setting (Glasgow, Vogt, \& Boles, 1999). The use and impact of the mindfulness meditation room on student engagement and learning will be examined as well. Various mindfulness interventions and programs (i.e., MBSR [mindfulness-based stress reduction], yoga, guided scans, breathing exercises, and self-compassion training) will be implemented to determine the impact of such training on holistic wellness, student retention, progression, and graduation (Abrams, 2008; Galantino, Galbavy, \& Quinn, 2008; Kabat-Zinn, 2003; Mendelson et al., 2010, Germer \& Neff, 2013). With increased demands on students to succeed in academics, perform in extra-curriculars, support themselves financially, and maintain social relationships, mindfulness training and accessible lab space to practice mindfulness can serve as a viable tool for the promotion of self-care, holistic wellness, and learning. 


\section{REFERENCES}

Abrams, H. (2008). Towards an understanding of mindful practices with children and adolescents in residential treatment. Residential Treatment for Children \& Youth, 24(1-2), 93-109.

https://doi.org/10.1080/08865710802147497

Bamber, M. D., \& Schneider, J. K. (2016). Mindfulness-based meditation to decrease stress and anxiety in college students: A narrative synthesis of the research. Educational Research Review, 18, 1-32. doi: https://doi.org/10.1016/j.edurev.2015.12.004

Biber, D. D., Brandenburg, G., Knoll, C., McBurse, S., Merem, A. M., \& Stewart, B. (2018). The Wolf Wellness Lab: A Model for Community Health and Wellness Promotion. Georgia Association for Health, Physical Education, Recreation and Dance, 50(2), 4-11. Retrieved from https://www.gahperd.org/publications.html

Broderick, P. C., \& Metz, S. (2009). Learning to BREATHE: A pilot trial of a mindfulness curriculum for adolescents. Advances in School Mental Health Promotion, 2(1), 35-46.

https://doi.org/10.1080/1754730X.2009.9715696

Bush, M. (2011). Mindfulness in higher education. Contemporary Buddhism, 12(01), 183-197. https://doi.org/10.1080/14639947.2011.564838

Conley, C. S., Durlak, J. A., \& Dickson, D. A. (2013). An evaluative review of outcome research on universal mental health promotion and prevention programs for higher education students. Journal of American College Health, 61(5), 286-301. https://doi.org/10.1080/07448481.2013.802237

Conley, C. S., Kirsch, A. C., Dickson, D. A., \& Bryant, F. B. (2014). Negotiating the transition to college: Developmental trajectories and gender differences in psychological functioning, cognitive-affective strategies, and social well-being. Emerging Adulthood, 2(3), 1-16. https://doi.org/10.1177/2167696814521808

Durlak, J. A., Weissberg, R. P., Dymnicki, A. B., Taylor, R. D., \& Schellinger, K. B. (2011). The impact of enhancing students' social and emotional learning: A meta-analysis of school-based universal interventions. Child Development, 82(1), 405-432. https://doi.org/10.1111/j.1467-8624.2010.01564.x

Dvořáková, K., Kishida, M., Li, J., Elavsky, S., Broderick, P. C., Agrusti, M. R., \& Greenberg, M. T. (2017). Promoting healthy transition to college through mindfulness training with first-year college students: Pilot randomized controlled trial. Journal of American College Health, 65(4), 259-267. https://doi.org/10.1080/07448481.2017.1278605

Eisenberg, D., Golberstein, E., \& Hunt, J. B. (2009). Mental health and academic success in college. The BE Journal of Economic Analysis \& Policy, 9(1). https://doi.org/10.2202/1935-1682.2191

Fink, J. E. (2014). Flourishing: Exploring predictors of mental health within the college environment. Journal of American College Health, 62(6), 380-388. https:/ / doi.org/10.1080/07448481.2014.917647

Finley, A., \& McNair, T. (2013). Assessing underserved students' engagement in high-impact practices. Washington, D.C.: Association of American Colleges and Universities.

Fisher, R. (2006). Still thinking: The case for meditation with children. Thinking Skills and Creativity, 1(2), $146-151$. https://doi.org/10.1016/j.tsc.2006.06.004 
Galantino, M., Galbavy, R., \& Quinn, L. (2008). Therapeutic effects of yoga for children: A systematic review of the literature. Pediatric Physical Therapy, 20(1), 66-80. https://doi.org/10.1097/PEP.0b013e31815f1208

Germer, C. K., \& Neff, K. D. (2013). Self-compassion in clinical practice. Journal of Clinical Psychology, 69(8), 856-867. https://doi.org/10.1002/jclp.22021

Glasgow, R. E., Vogt, T. M., \& Boles, S. M. (1999). Evaluating the public health impact of health promotion interventions: the RE-AIM framework. American Journal of Public Health, 89(9), 1322-1327. https://doi.org/10.2105/AJPH.89.9.1322

Goss, H. B., Cuddihy, T. F., \& Michaud-Tomson, L. (2010). Wellness in higher education: A transformative framework for health related disciplines. Asia-Pacific Journal of Health, Sport and Physical Education, 1(2), 29-36. https://doi.org/10.1080/18377122.2010.9730329

Grossman, P., \& Van Dam, N. T. (2011). Mindfulness, by any other name: Trials and tribulations of sati in western psychology and science. Contemporary Buddhism, 12, 219-239. doi: https://doi.org/10.1080/14639947.2011.564841

Hager, R., George, J. D., LeCheminant, J. D., Bailey, B. W., \& Vincent, W. J. (2012). Evaluation of a university general education health and wellness course delivered by lecture or online. American Journal of Health Promotion, 26(5), 263-269. https://doi.org/10.4278/ajhp.101020-QUAN-344

Hart Research Associates. (2009). Trends and emerging practices in general education. Washington, D.C.: Author

Kabat-Zinn, J. (1994). Wherever you go, there are you: Mindfulness meditation in everyday life. New York, NY: Hyperion.

Kabat-Zinn, J. (2003). Mindfulness-based interventions in context: Past, present, and future. Clinical Psychology: Science and Practice, 10(2), 144-156. https://doi.org/10.1093/clipsy.bpg016

Kang, C., \& Whittingham, K. (2010). Mindfulness: A dialogue between Buddhism and clinical psychology. Mindfulness, 1(3), 161-173. https://doi.org/10.1007/s12671-010-0018-1

Lynch, S., Gander, M. L., Kohls, N., Kudielka, B., \& Walach, H. (2011). Mindfulness-based coping with university life: A non-randomized wait-list-controlled pilot evaluation. Stress and Health, 27(5), 365-375. https://doi.org/10.1002/smi.1382

Mendelson, T., Greenberg, M., Dariotis, J., Gould, L., Rhoades, B., \& Leaf, P. (2010). Feasibility and preliminary outcomes of a school-based mindfulness intervention for urban youth. Journal of Abnormal Child Psychology, 38(7), 985-994. https://doi.org/10.1007/s10802-010-9418-x

National Wellness Institute. (n.d.). The six dimensions of wellness. Retrieved from http://www.nationalwellness.org/ index.php?id_tier $=2 \& i d \_c=25$

Porter, S. R., \& Swing, R. L. (2006). Understanding how first-year seminars affect persistence. Research in Higher Education, 47(1), 89-109. https://doi.org/10.1007/s11162-005-8153-6

Quaye, S. J., \& Harper, S. R. (Eds.). (2014). Student engagement in higher education: Theoretical perspectives and practical approaches for diverse populations. Routledge. https://doi.org/10.4324/9780203810163

Regehr, C., Glancy, D., \& Pitts, A. (2013). Interventions to reduce stress in university students: A review and metaanalysis. Journal of Affective Disorders, 148(1), 1-11. https://doi.org/10.1016/j.jad.2012.11.026 
Rosenstreich, E., \& Margalit, M. (2015). Loneliness, mindfulness, and academic achievements: A moderation effect among first-year college students. The Open Psychology Journal, 8(1). https://doi.org/10.2174/1874350101508010138

Schonert-Reichl, K. A., \& Lawlor, M. S. (2010). The effects of a mindfulness-based education program on pre- and early adolescents' well-being and social and emotional competence. Mindfulness, 1(3), 137-151. https://doi.org/10.1007/s12671-010-0011-8

Shapiro, S. L., Brown, K. W., \& Astin, J. (2011). Toward the integration of meditation into higher education: A review of research evidence. Teachers College Record, 113(3), 493-528. Retrieved from http://www.contemplativemind.org/files/MedandHigherEd.pdf.

Shapiro, S., Carlson, L., Astin, J., \& Freedman, B. (2006). Mechanisms of mindfulness. Journal of Clinical Psychology, 62(3), 373-386. https://doi.org/10.1002/jclp.20237

Stebleton, M. J., Soria, K. M., \& Huesman Jr, R. L. (2014). First-generation students' sense of belonging, mental health, and use of counseling services at public research universities. Journal of College Counseling, 17(1), 6-20. https://doi.org/10.1002/j.2161-1882.2014.00044.x

Strout, K. A., \& Howard, E. P. (2012). The six dimensions of wellness and cognition in aging adults. Journal of Holistic Nursing, 30(3), 195-204. https://doi.org/10.1177/0898010112440883

Tinto, V. (1997). Classrooms as communities. Journal of Higher Education, 68(6), 599-623. https://doi.org/10.1080/00221546.1997.11779003

Whitehall, A. P., Hill, L. G., Yost, D. M., \& Kidwell, K. K. (2018). Being smart is not enough to ensure success: Integrating personal development into a general education course. The Journal of General Education, 65(3-4), 241-263. https://doi.org/10.5325/jgeneeduc.65.3-4.0241

Zins, J. E., Weissberg, R. P., Wang, M. C., \& Walberg, H. J. (Eds.). (2004). Building academic success on social and emotional learning: What does the research say? New York: Teachers College Press.

Address author correspondence to:

Duke D. Biber, PhD

Assistant Professor of Health and Community Wellness

Department of Sport Management, Wellness, and Physical Education

University of West Georgia

Carrollton, GA 30118

Email: Dbiber@westga.edu

Phone: 678-839-5141 